\title{
Mediating the Fate of Cancer Cell Uptake: Dual-Targeted Magnetic Nanovectors with Biotin and Folate Surface Ligands
}

\author{
Shaista llyas,,${ }^{a,}{ }^{*}$ Nighat K. Ullah, ${ }^{a}$ Muhammad llyas, ${ }^{b}$ Kerstin Wennhold, $, c, d$ Maria Iqbal, e,f \\ Hans A. Schlößer, ${ }^{c, d}$ Muhammad S. Hussain,e,f and Sanjay Mathur a.* \\ ${ }^{a}$ Institute of Inorganic Chemistry, University of Cologne, Greinstraße 6, 50939, Cologne, Germany \\ ${ }^{b}$ Professorship for Population Genetics, Department of Life Science Systems, Technical University of Munich, Liesel-Beckmann \\ Straße 2, 85354 Freising, Germany \\ ${ }^{\circ}$ Center for Molecular Medicine Cologne and Translational Immunology, University Hospital Cologne, 50931 Cologne, Germany \\ ${ }^{d}$ Medical Microbiology, Immunology and Hygiene, University Hospital Cologne, Goldenfels straße 19-21, 50935 Cologne, Germany \\ ${ }^{e}$ Institute of Biochemistry I, Center for Molecular Medicine, University of Cologne, Joseph-Stelzmann-Straße 52, 50931 Cologne, \\ Germany \\ ${ }^{f}$ Cologne Center for Genomics (CCG), University of Cologne, Weyertal 115b, 50931 Cologne, Germany \\ ${ }^{*}$ Correspondence: sanjay.mathur@uni-koeln.de \\ silyas@uni-koeln.de
}

Figure S1. TG/DTA analysis of $\mathrm{FA}-\mathrm{Fe}_{3} \mathrm{O}_{4}$ and $\mathrm{FA}-\mathrm{Fe}_{3} \mathrm{O}_{4}$-Biotin NPs.

Figure S2. FTIR spectrum of dopamine molecule.

Figure S3. FTIR spectrum of folic acid molecule.

Figure S4. Zeta potential measurement of dopa- $\mathrm{Fe}_{3} \mathrm{O}_{4} \mathrm{NPs}$ in water.

Figure S5. Zeta potential measurement of $\mathrm{FA}-\mathrm{Fe}_{3} \mathrm{O}_{4}$-Biotin NPs in water.

Figure S6. UV/vis spectrum shows FITC attachment on Dopa- $\mathrm{Fe}_{3} \mathrm{O}_{4} \mathrm{NPs}$.

Figure S7. UV/vis spectrum of $\mathrm{FA}-\mathrm{Fe}_{3} \mathrm{O}_{4}$-Biotin without streptavidin Rhodamine.

Figure S8. UV/vis spectrum of $\mathrm{FA}-\mathrm{Fe}_{3} \mathrm{O}_{4}$-Biotin with streptavidin Rhodamine 


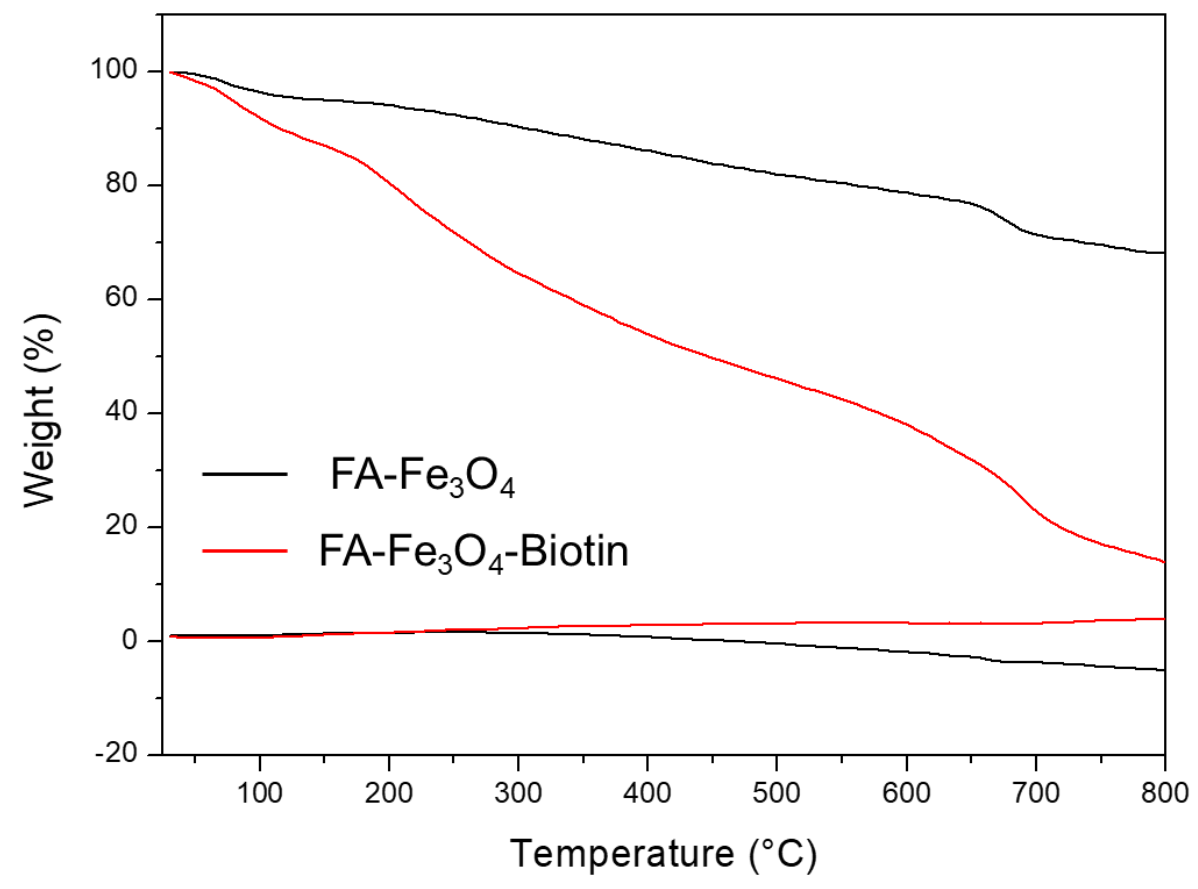

Figure S1. TG/DTA analysis of $\mathrm{FA}-\mathrm{Fe}_{3} \mathrm{O}_{4}$ and $\mathrm{FA}-\mathrm{Fe}_{3} \mathrm{O}_{4}$-Biotin NPs indicating the enhanced surface moieties after surface bioconjugation. 


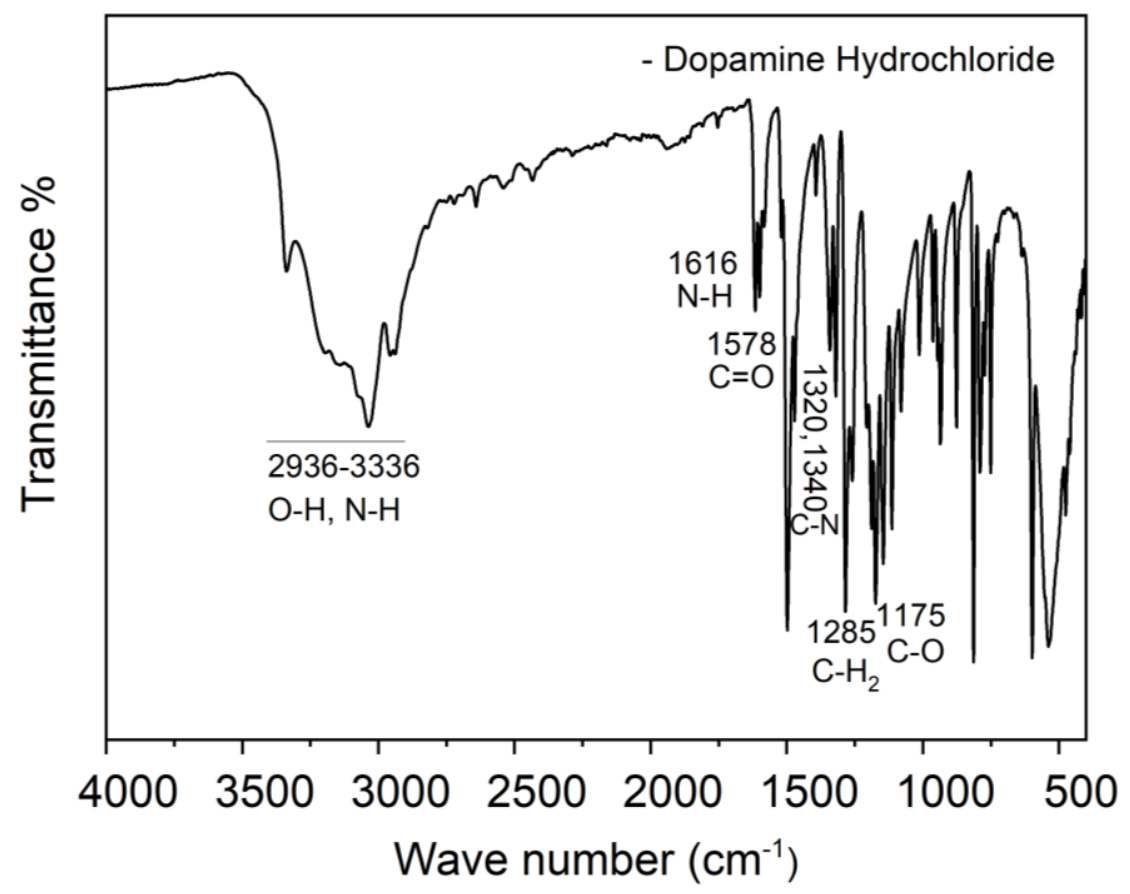

Figure S2. FTIR spectrum of dopamine molecule.

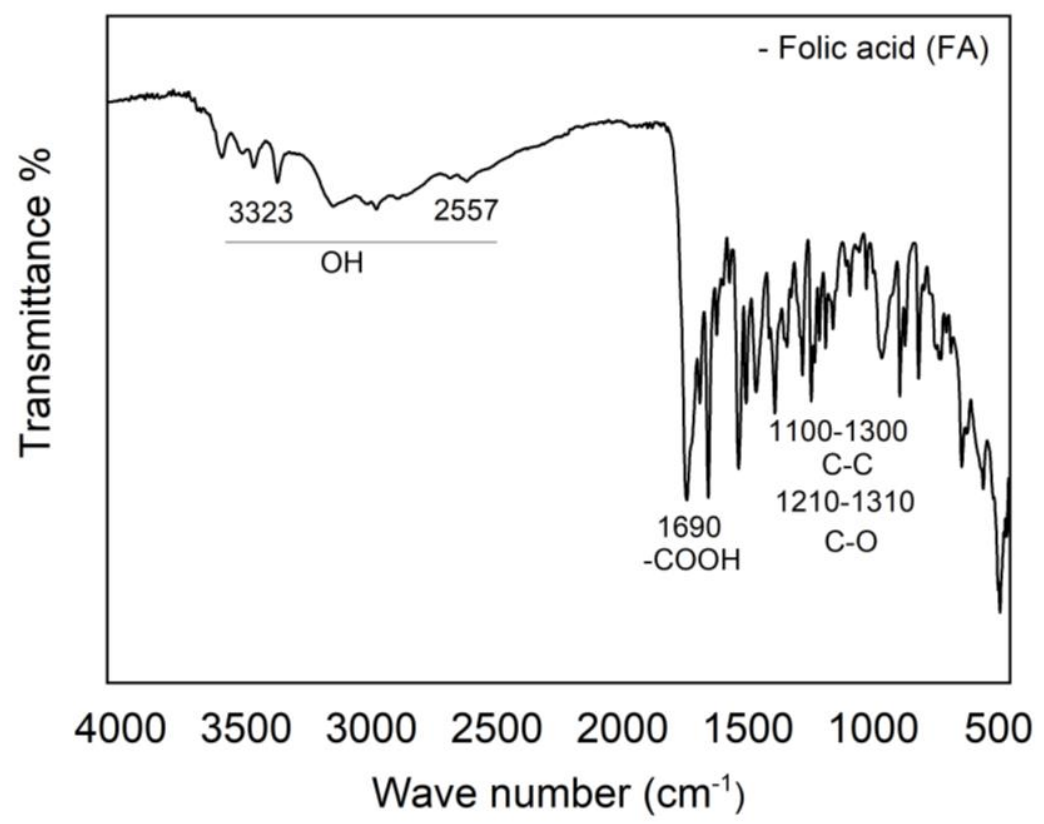

Figure S3. FTIR spectrum of folic acid molecule. ${ }^{1}$ 


\section{Zeta potential distribution}

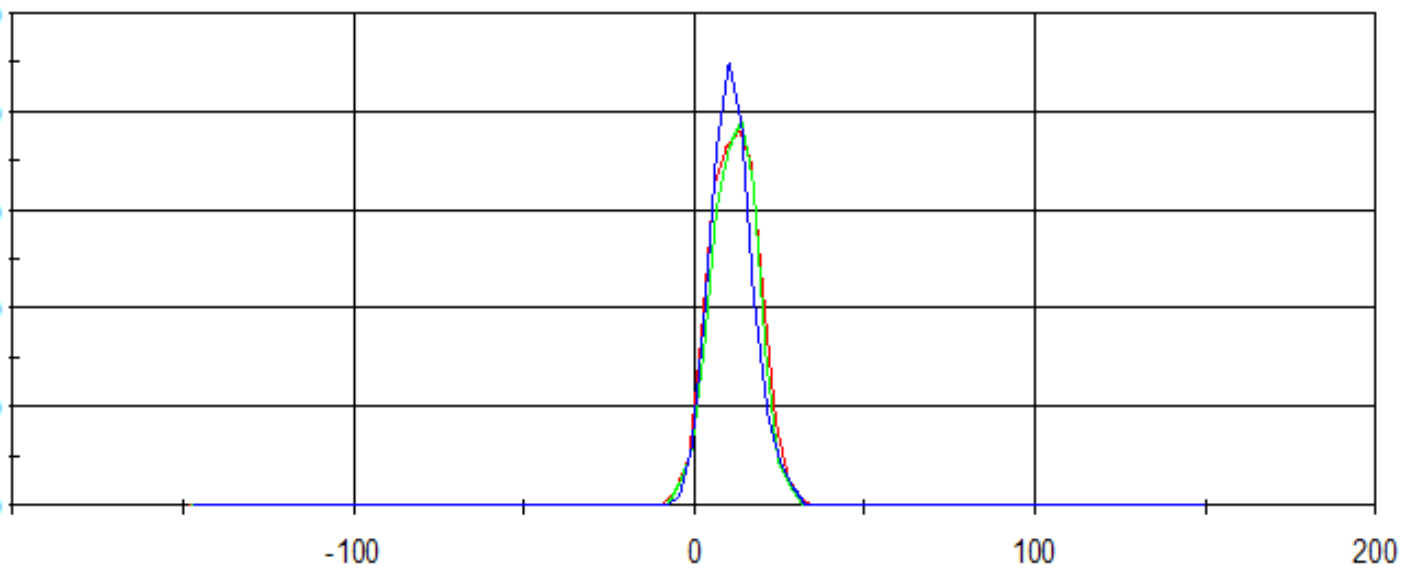

Apparent zeta potential $\mathrm{mV}$

Figure S4. Zeta potential measurement of dopa- $\mathrm{Fe}_{3} \mathrm{O}_{4} \mathrm{NPs}$ in water. The average value of $+12 \mathrm{mV}$ indicated the presence of free amino groups on the surface of $\mathrm{Fe}_{3} \mathrm{O}_{4} \mathrm{NPs}$

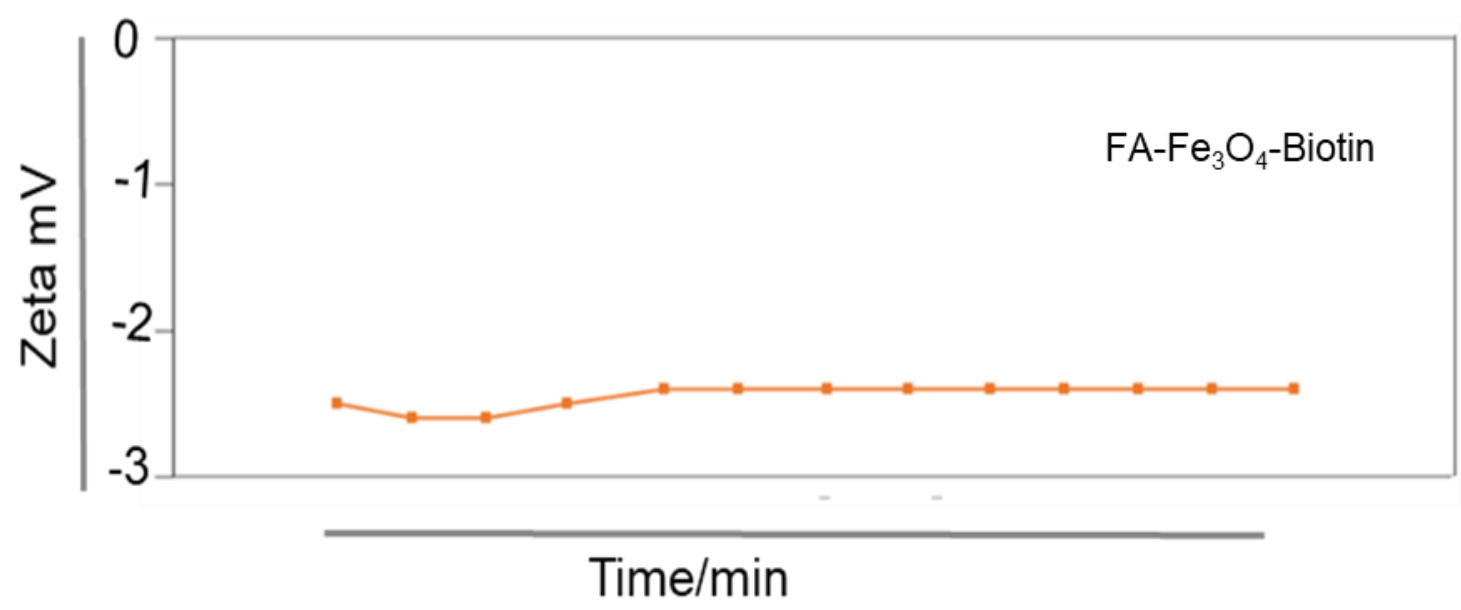

Figure S5. Zeta potential measurement of $\mathrm{FA}-\mathrm{Fe}_{3} \mathrm{O}_{4}$-Biotin NPs in water. 


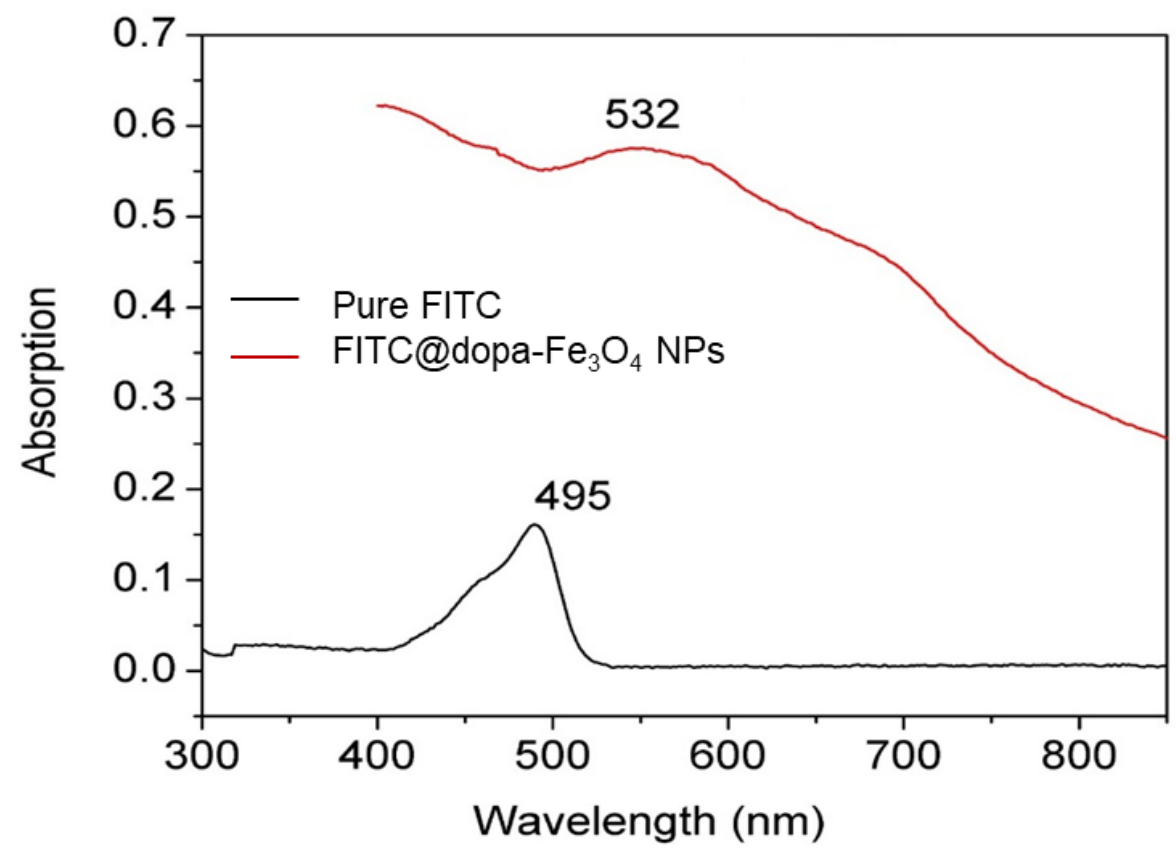

Figure S6. UV/vis spectrum shows FITC attachment on Dopa-Fe $\mathrm{O}_{4} \mathrm{NPs}$. Black line shows the absorption at $495 \mathrm{~nm}$ for pure FITC. After its attachment, red lines in the upper graph designate a shift in absorption which appears at $532 \mathrm{~nm}$.

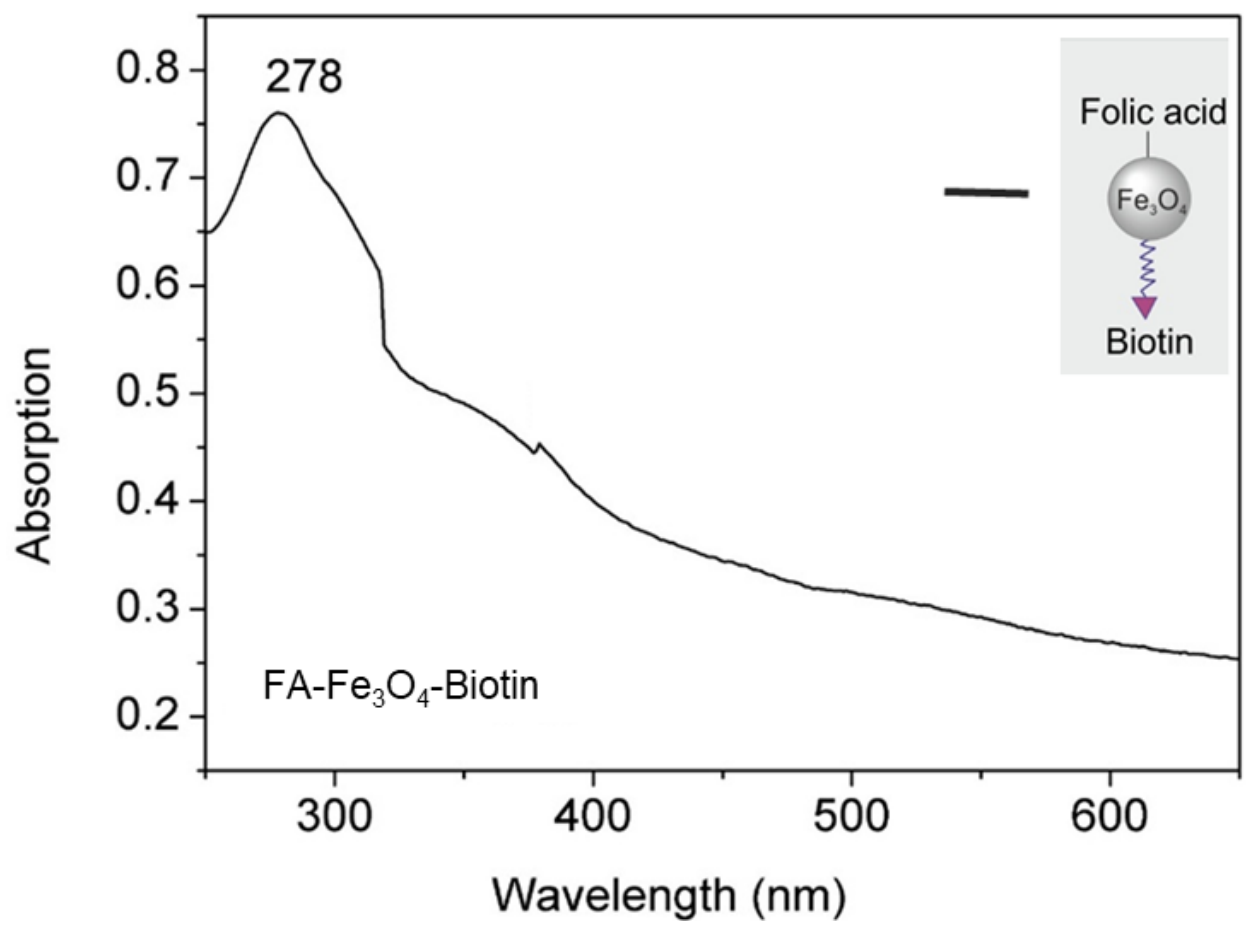

Figure S7. UV/vis spectrum of $\mathrm{FA}-\mathrm{Fe}_{3} \mathrm{O}_{4}$-Biotin without streptavidin Rhodamine. The two absorption peaks at $287 \mathrm{~nm}$ shows folic acid presence on NPs, (379 $\mathrm{nm}$ is an artifact). 


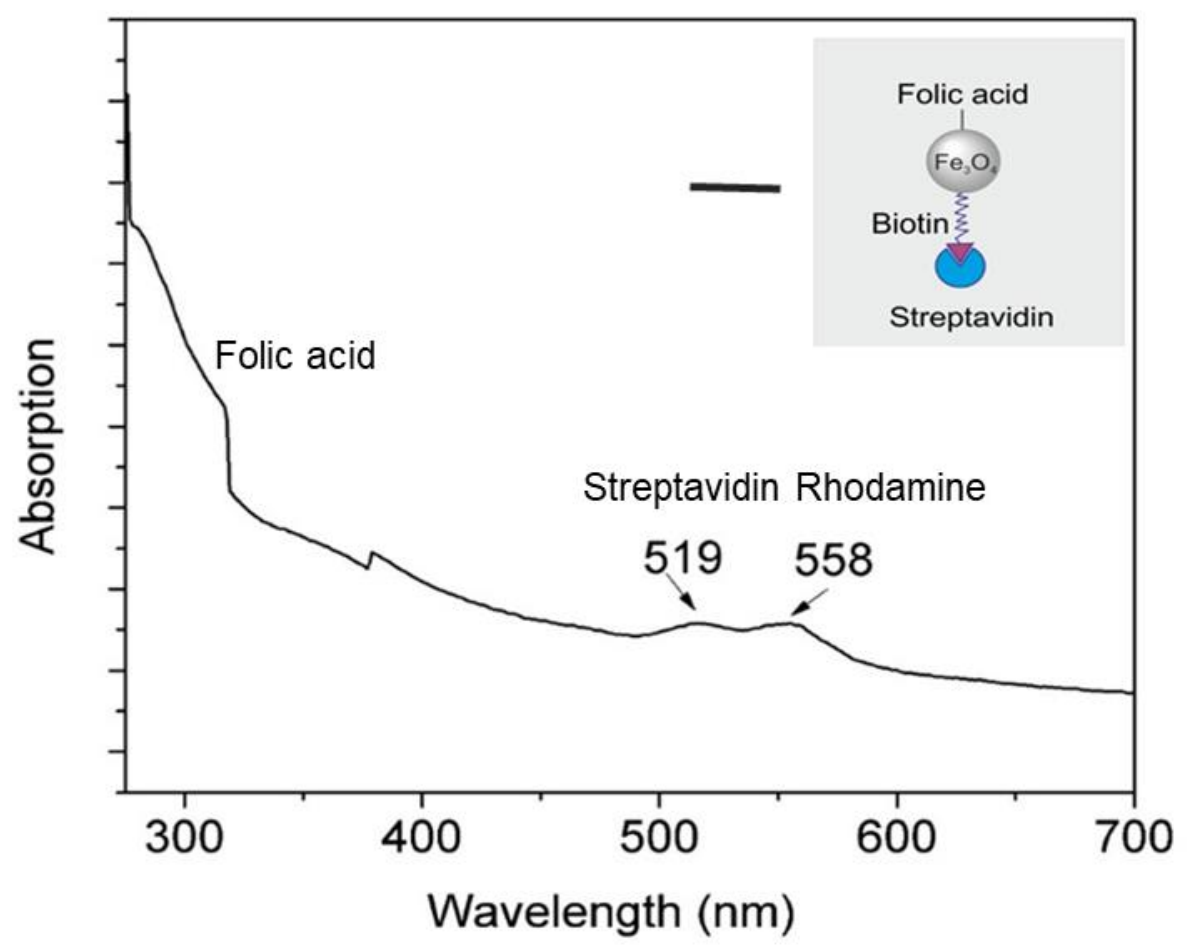

Figure S8. UV/vis spectrum of $\mathrm{FA}-\mathrm{Fe}_{3} \mathrm{O}_{4}$-Biotin with streptavidin Rhodamine. The results show the binding of biotin and folic acid on the surface of Dopa- $\mathrm{Fe}_{3} \mathrm{O}_{4} \mathrm{NPs}$. The absorption bands at 519 and $558 \mathrm{~nm}$ specify a bond between biotin and streptavidin Rhodamine thus can be related to the biotin immobilization on NPs. In addition, existence of folic acid is specified by an absorption peak around $310 \mathrm{~nm}$, (380 nm is an artifact).

\section{References:}

İnce, İ., Yıldırım, Y., Güler, G., Medine, E. İ., Ballıca, G., Kuşdemir, B. C., \& Göker, E. Synthesis and characterization of folic acid-chitosan nanoparticles loaded with thymoquinone to target ovarian cancer cells. J Radioanal Nucl Chem. (2020), 324, 1-15. 